\title{
Resistência natural da madeira de Tectona grandis em ensaio de laboratório
}

\author{
Natural resistance of Tectona grandis wood in laboratory assay
}

\author{
Javan Pereira Motta ${ }^{\mathrm{I}}$ José Tarcísio da Silva Oliveira ${ }^{\mathrm{II}}$ Juarez Benigno Paes ${ }^{\mathrm{II}}$ \\ Rejane Costa Alves III Graziela Baptista Vidaurre Dambroz ${ }^{\text {II }}$
}

\section{RESUMO}

O objetivo da pesquisa foi avaliar a resistência natural da madeira de teca (Tectona grandis) a fungos e térmitas xilófagos em condições de laboratório. As árvores empregadas possuíam 15 anos de idade, provenientes de um plantio da Empresa Celulose Nipo Brasileira-CENIBRA S.A., localizada no município de Belo Oriente, Estado de Minas Gerais. Para a determinação da resistência natural da madeira a agentes xilófagos, foram realizados ensaios de apodrecimento acelerado em laboratório com os fungos Postia placenta, Neolentinus lepideus, Polyporus fumosus, e de preferência alimentar com cupins subterrâneos Nasutitermes sp. Corpos de prova foram retirados em quatro posições no sentido medula casca: cerne interno (próximo da medula), cerne intermediário, cerne externo (próximo ao alburno) e no alburno, na altura de 1,30m do nível do solo e submetidos à ação dos fungos por 13 semanas e cupins por 45 dias. Constatouse que o cerne da madeira de teca proveniente do Vale do Rio Doce, Minas Gerais, foi altamente resistente, tendo o cerne interno sido menos resistente que as demais porções do cerne à ação dos agentes xilófagos, enquanto a madeira de alburno foi classificada como de resistência moderada (Polyporus fumosus) ou resistente (Postia placenta e Neolentinus lepideus).

Palavras-chave: madeira de teca, térmitas, fungos, durabilidade natural.

\section{ABSTRACT}

This research aimed to evaluate the natural resistance of teak wood (Tectona grandis) to xylophagous fungi and termites in laboratory conditions. It was used trees with fifteen years old, from a plantation of the Forest Enterprise Celulose Nipo Brasileira-CENIBRA S.A., located in Belo Oriente, Minas Gerais
State, Brazil. To determine the natural resistance of teak wood in laboratory were employed the Postia placenta, Neolentinus lepideus, Polyporus fumosus and Fomes connatus fungi and to termites resistance was employed the feeding preference assay with subterranean termites Nasutitermes sp. Samples were taken from four positions in the stem (heartwood near the pith, heartwood intermediate, outer heartwood and sapwood) at 1,30m to soil level and submitted to the action of fungi for thirteen weeks and termites for 45 days. It was found that the heartwood of teakwood from the Vale do Rio Doce, Minas Gerais State, Brazil was highly resistant. The internal heartwood was less resistant than the other portions of the heartwood to action of wood decay agents, while the sapwood was classified as moderately resistant (Polyporus fumosus) or resistant (Postia placenta and Neolentinus lepideus).

Key words: teak wood, termites, fungi, natural durability.

\section{INTRODUÇÃO}

Nenhuma espécie de madeira, nem mesmo as de reconhecida durabilidade natural, é capaz de resistir, indefinidamente, às intempéries e variações das condições ambientais (SILVA, 2005). De acordo com a Associação Brasileira da Indústria de Madeira Processada Mecanicamente - ABIMCI (2004), a vida útil da madeira maciça ou reconstituída varia, dependendo da espécie, da quantidade de alburno presente, do seu uso e das condições ambientais às quais está exposta.

IPrograma de Pós-graduação em Ciência e Tecnologia da Madeira, Departamento de Ciências Florestais - Universidade Federal de Lavras Campus Universitário, Caixa Postal 3037, 37200-000, Lavras, MG - jpereiramotta@yahoo.com.br IDepartamento de Engenharia Florestal - Universidade Federal do Espírito Santo - Av. Governador Lindemberg, 316, Centro, 29550-000, Jerônimo Monteiro, ES, Brasil.

IIIPrograma de Pós-graduação em Engenharia de Estruturas, Departamento de Estruturas, Universidade Federal de Minas Gerais - Av. Antônio Carlos, 6.627 - Campus Pampulha - Escola de Engenharia, 31270-901, Belo Horizonte, MG,Brasil. 
A degradação da madeira por insetos ou microrganismos é uma etapa fundamental na reciclagem de nutrientes dentro de um ecossistema, colaborando para o equilíbrio entre a diversidade de formas vivas existentes na natureza (JANKOWSKY, 1990). No entanto, os agentes biológicos são causadores de grandes prejuízos à utilização da madeira (SGAI, 2000).

Os fungos e térmitas são exemplos de xilófagos mais comuns, pela facilidade do surgimento desses agentes na madeira quando as condições são favoráveis. Os fungos podem decompor totalmente a madeira ou apenas causar manchas, são classificados como apodrecedores, emboloradores e manchadores. Já os térmitas são, entre os insetos, considerados os principais responsáveis em causar danos à madeira no mundo e, conforme seus hábitos de vida são classificados como subterrâneos, de madeira seca e de madeira úmida (ROCHA, 2001).

A Tectona grandis, conhecida como teca, situa-se dentre as preferidas para o reflorestamento, para a produção de madeira sólida e laminados, encontrando cultivos distribuídos pelo mundo, inclusive no Brasil. Sua madeira é considerada imune à ação dos fungos apodrecedores e insetos, podendo ser enterrada, exposta ao tempo ou à água do mar sem sofrer grandes danos.

O conhecimento sobre a durabilidade natural e restrições de uso da madeira de teca oriunda de plantios brasileiros é importante, visto que fornece informações básicas a respeito da utilização dos seus produtos sob diferentes condições de exposição a agentes biodeterioradores, como fungos e térmitas, responsáveis pelos maiores danos econômicos à madeira. Portanto, este trabalho teve como objetivo avaliar a resistência natural da madeira de Tectona grandis com 15 anos de idade, proveniente do Vale do Rio Doce, Minas Gerais, a organismos xilófagos em condições de laboratório.

\section{MATERIAL E MÉTODOS}

O material estudado foi procedente da espécie Tectona grandis L.f., com idade de aproximadamente 15 anos, proveniente de uma plantação da Empresa Florestal Celulose Nipo Brasileira - CENIBRA S.A., no município de Belo Oriente no Vale do Rio Doce - Minas Gerais, que integra o Colar Metropolitano do Vale do Aço, localizada a $19^{\circ} 15^{\prime} 00^{\prime \prime}$ Sul $42^{\circ} 22^{\prime} 30^{\prime \prime}$ Oeste.

Foram obtidas, de povoamento não desbastado, cinco árvores com diâmetro à altura do peito (DAP) tomado a $1,30 \mathrm{~m}$ do solo, de $28,0 \mathrm{~cm}$. Cada árvore deu origem a duas toras de aproximadamente $3,0 \mathrm{~m}$ de comprimento. Posteriormente, todas as toras foram desdobradas, transformadas em tábuas com aproximadamente $3,0 \mathrm{~cm}$ de espessura, $3,0 \mathrm{~m}$ de comprimento e largura variável, além de um pranchão central. Após a secagem ao ar livre do pranchão central, foram retiradas amostras em quatro posições radiais no sentido medula casca (1 - cerne interno (próximo da medula), 2 - cerne intermediário, 3 - cerne externo (próximo do alburno) e 4 - alburno).

Para a determinação da resistência natural da madeira de teca a agentes xilófagos, foram realizados ensaios de apodrecimento acelerado em laboratório e de preferência alimentar a térmitas.

Para execução do ensaio de apodrecimento acelerado em laboratório seguiram-se as especificações da American Society for Testing and Materials - ASTM D-1413 (2007). Foram utilizados corpos de prova com dimensões de 1,9x1,9x1,9cm. Foram utilizadas culturas puras de três fungos, sendo dois de podridão parda, Postia placenta (Fr.) M. Larsen et Lombard = (Madison FPL 698) e o Neolentinus lepideus (Fr.) Redhead e Ginns (Forintek Canada Corporation $44 \mathrm{~J}$ ), e um de podridão branca, o Polyporus fumosus Pers. Ex. Fr. (Forintek Canada Corporation 496A).

Frascos de vidro de $500 \mathrm{~mL}$ de capacidade foram preenchidos com $350 \mathrm{~g}$ de solo ( $\mathrm{pH}$ de 6,63 e capacidade de retenção de água de 33,48\%). Após o preenchimento, foram adicionados $110 \mathrm{~mL}$ de água destilada para umedecimento do solo, adicionados dois alimentadores de madeira de Pinus sp., e esterilizados a $121 \pm 2^{\circ} \mathrm{C}$, por uma hora. Após o resfriamento, fragmentos obtidos de culturas puras dos fungos, citados, foram inoculados sobre os alimentadores. Após o desenvolvimento e colonização do solo pelo fungo (ASTM D-2017, 2005), foram adicionados os corpos de prova, secos em estufa à temperatura de $103 \pm 2^{\circ} \mathrm{C}$, por 48 horas e posteriormente pesados. Foram empregadas oito repetições para cada posição, totalizando 24 amostras por fungo.

Os frascos foram mantidos por 13 semanas em sala climatizada $\left(27 \pm 2^{\circ} \mathrm{C}\right.$ e $65 \pm 5 \%$ de umidade relativa). Foram mantidos frascos com corpos de prova para avaliação da perda de massa operacional, sem a presença de fungos, que foram utilizados como fator de correção, para permitir que a perda de massa sofrida pelas amostras tenha sido em decorrência do apodrecimento e não de outros fatores operacionais.

Para execução de o ensaio de preferência alimentar, seguiu-se a metodologia descrita por PAES et al. (2006, 2007b, 2010) e SUPRIANA (1985). Foram utilizados corpos de prova com dimensões 
de 2,54×0,64×10,16cm (radial $x$ tangencial $x$ longitudinal) e corpos de prova de Pinus sp. utilizados como padrão de comparação. Os corpos de prova foram secos a temperatura de $103 \pm 2^{\circ} \mathrm{C}$, até atingirem massa constante, pesados em uma balança de $0,01 \mathrm{~g}$ de precisão. Os valores de massa seca foram utilizados no cálculo da perda de massa da madeira. Foram utilizadas 10 repetições para cada uma das posições anteriormente citadas.

No ensaio de preferência alimentar, foi utilizado o cupim de solo Nasutitermes sp. Para a montagem do ensaio, os corpos de prova foram dispostos em uma caixa d'água de $1000 \mathrm{~L}$, que continha uma camada de aproximadamente $15 \mathrm{~cm}$ de areia úmida. As amostras foram distribuídas segundo um delineamento em blocos casualizados, contendo 10 repetições, quatro tratamentos (posições), totalizando 40 corpos de prova, além de 10 corpos de prova de Pinus sp. (de acordo especificações ASTM D-3345, 2008).

A colônia de cupins (Figura 1) foi coletada em Santa Angélica, Alegre - ES, e disposta em uma grelha de $50 \times 40 \times 5 \mathrm{~cm}$ (comprimento $\times$ largura $\times$ espessura), apoiada em dois tijolos de quatro furos, postos sobre a camada de areia. Os corpos de prova ficaram expostos à ação dos cupins durante 45 dias, em um galpão, sob condições de temperatura de $27 \pm 2^{\circ} \mathrm{C}$ e umidade relativa de $62 \pm 5 \%$. Após o ensaio, eles foram secos em estufa de ventilação forçada a $103 \pm 2{ }^{\circ} \mathrm{C}$ e pesados, para se avaliar a porcentagem de perda de massa.

Avaliou-se a resistência natural da madeira de teca em função da perda de massa e do desgaste provocado pelos cupins aos corpos de prova (de acordo com as especificações da ASTM D-3345, 2008). A perda de massa foi corrigida por meio das amostras de perda de massa operacional.

Os valores em porcentagem de perda de massa foram transformados em arcsen $\sqrt{\text { Perdademassa/100 }}$ e os do desgaste (nota) em $\sqrt{\text { Nota }+0,5}$ para permitir a homogeneidade das variâncias, de acordo com STEEL \& TORRIE (1980). Na análise e avaliação dos ensaios, o teste de Tukey a 5\% de significância foi aplicado.

\section{RESULTADOS E DISCUSSÃO}

Observa-se (Tabela 2) que a posição referente ao alburno foi mais atacada pelos fungos, diferindo estatisticamente a 5\% de significância pelo teste de Tukey. A durabilidade do cerne da teca devese à tectoquinona, um preservativo natural contido nas células da madeira, ausente no alburno (RUDMAN et al., 1958).

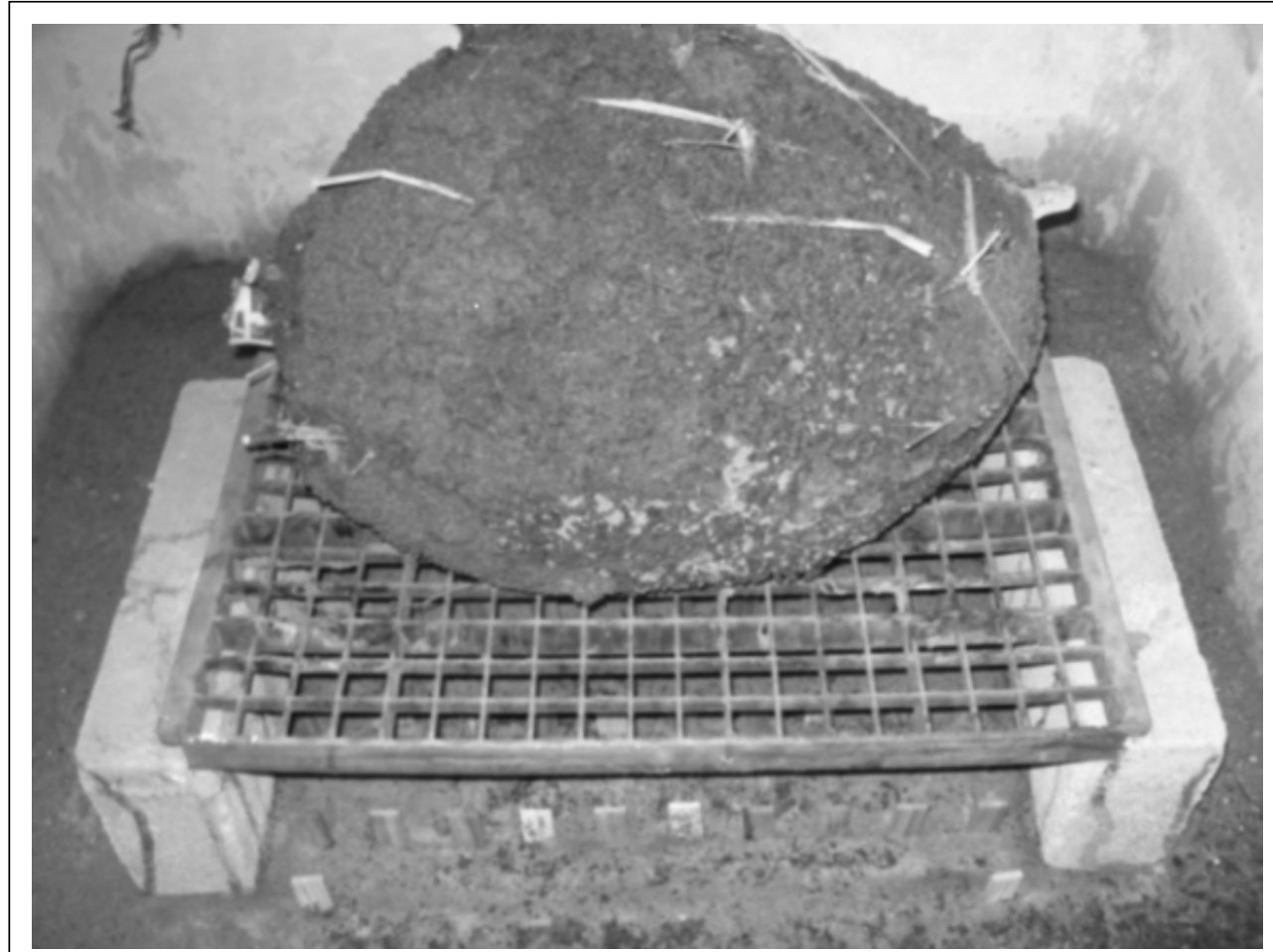

Figura 1 - Colônia de cupins Nasutitermes sp. no ensaio de preferência alimentar. 
Comparados os resultados da perda de massa (Tabela 2) com as classes de resistência da madeira a fungos xilófagos (Tabela 1), a madeira de Tectona grandis plantada no Vale do Rio Doce, Minas Gerais, é classificada nas posições cerne interno, cerne intermediário e cerne externo como altamente resistente para todos os fungos testados. Já para a madeira de alburno, a classificação é variável, como resistente aos fungos Postia placenta e Neolentinus lepideus e de resistência moderada ao fungo Polyporus fumosus.

Esse comportamento foi observado por PAES (2002), que, ao estudar a resistência natural da madeira de Corymbia maculata aos fungos Postia placenta, Neolentinus lepideus e Polyporus fumosus, em condições de laboratório, verificou que esses fungos foram mais agressivos na posição mais externa da madeira, madeira composta por alburno. PAES et al. (2007a) verificaram, para os fungos Polyporus fumosus e Postia placenta, que a madeira de Tectona grandis é muito resistente, quando se analisa a madeira nas posições cerne interno à cerne intermediário e cerne externo, mas com resistência moderada na posição mais externa, composta exclusivamente de alburno.

De acordo com CLAUSEN (2010), o alburno de praticamente todas as espécies tem baixa resistência à degradação e, geralmente, tem uma vida útil de curta duração sob condições que favorecem a deterioração. A resistência à deterioração natural do cerne é principalmente afetada por diferenças entre os extrativos da madeira, do tipo de fungo e das condições de exposição da madeira.

Tabela 1 - Classes de resistência da madeira a fungos xilófagos.

\begin{tabular}{ccc}
\hline Perda de massa (\%) & Massa residual (\%) & Classes de resistência \\
\hline $0-10$ & $90-100$ & Altamente resistente \\
$11-24$ & $76-89$ & Resistente \\
$25-44$ & $56-75$ & Resistência moderada \\
$\geq 45$ & $\leq 55$ & Não resistente
\end{tabular}

Fonte: ASTM D-2017 (ASTM, 2005).

Tabela 2 - Perda de massa (\%) da madeira de Tectona grandis submetida aos fungos xilófagos.

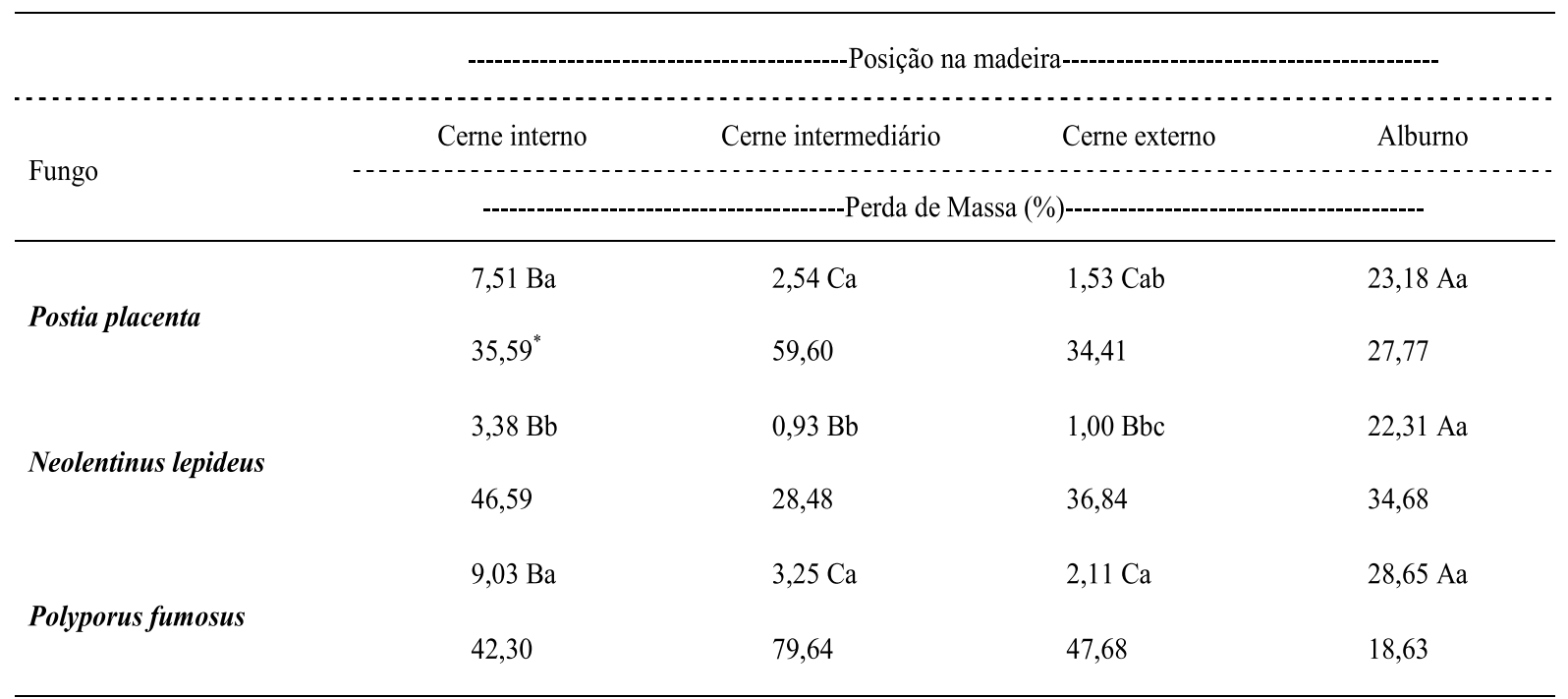

* Coeficientes de variação (\%). Médias seguidas pela mesma letra maiúscula na horizontal, ou por uma mesma letra minúscula na vertical, não diferem estatisticamente entre si (Tukey; $\mathrm{P}>0,05$ ). 
BHAT et al. (2005), ao verificarem a durabilidade da madeira de teca contra fungos de podridão parda (Gloeophyllum trabeum e Polyporus palustris) e de podridão branca (Pycnoporus sanguineus, Trametes hirsuta e $T$. versicolor) de árvores com 35 anos de idade, provenientes de diferentes plantações em Nilambur, localizada em Kerala, Índia, verificaram que a resistência natural da madeira de teca depende principalmente da espécie de fungo e posição da madeira no tronco (medula, cerne, alburno) e da interação entre esses fatores.

Os valores médios (Tabela 2) de perda de massa por fungo em cada posição, o Polyporus fumosus e Postia placenta foram os que mais causaram danos à madeira de teca em todas as posições radiais analisadas.

A madeira de teca, utilizada neste estudo, possui alta resistência aos fungos avaliados nas posições cerne interno, cerne intermediário e cerne externo. Esse resultado é importante principalmente para a madeira do cerne periférico, que é mais valorizada por apresentar propriedades físicas e mecânicas superiores. Esses resultados podem ser comprovados por CLAUSEN (2010), que classifica o cerne da madeira de teca como altamente resistente a fungos.

Segundo FINDLAY (1985), o cerne periférico é a parte do lenho mais resistente a organismos xilófagos. Por outro lado, a posição mais interna próxima à medula é a região com madeira de menor resistência ao ataque de organismos xilófagos (Tabela 2). Essa menor durabilidade pode ser explicada pela perda de eficiência dos extrativos ao longo do tempo, formando madeira mais susceptível ao ataque de organismos xilófagos ou pela quantidade de extrativos existentes, uma vez que a parede celular da madeira mais jovem (primeiros anos de crescimento) é menos espessa que da madeira adulta.

$\mathrm{Na}$ tabela 3, encontram-se os valores médios e a comparação múltipla entre médias para a perda de massa e desgaste na madeira de teca, proveniente do Vale do Rio Doce, Minas Gerais, provocado pelo cupim de solo Nasutitermes sp. PAES et al. (2007a), ao analisarem a resistência da madeira de teca a cupins subterrâneos em diferentes posições radiais no tronco, a classificaram como resistente, mas o alburno apresentou maior perda de massa $(12,87 \%)$ em relação às demais posições avaliadas.

RUDMAM et al. (1967), ao estudarem a qualidade da madeira de teca, proveniente de plantações na Nova Guiné, Indonésia e Burma, em árvores com 13, 14 e 168 anos de idade, respectivamente, verificaram que a resistência do cerne intermediário e externo aos cupins subterrâneos Coptotermes lacteus variou conforme a idade. Para árvores jovens, 13 e 14 anos, a perda de massa no cerne intermediário foi superior a $60 \%$ e, no cerne externo, não passou de $20 \%$. Para árvores adultas, com idade de 168 anos, a perda de massa no cerne intermediário foi de $15 \%$, e no cerne externo de $4 \%$. Esses resultados foram superiores aos encontrados para a madeira de teca proveniente do Vale do Rio Doce, Minas Gerais, para o cupim do gênero Nasutitermes.

Para o desgaste provocado pelos cupins no alburno, verifica-se nota igual a 0,78 (ASTM D-2017, 2008). As demais posições receberam notas altas, com destaque para o cerne externo que, além de receber nota alta $(9,56)$, obteve em média menor perda de massa $(0,43 \%)$. Esse resultado indica a elevada resistência da madeira à ação de térmitas, principalmente do gênero Nasutitermes.

Tabela 3 - Perda de massa e desgaste causado pelo cupim Nasutitermes sp.

\begin{tabular}{|c|c|c|c|c|}
\hline & Cerne interno & Cerne intermediário & Cerne externo & Alburno \\
\hline \multirow{2}{*}{ Perda de massa $(\%)$} & $1,28 \mathrm{~b}$ & $0,55 \mathrm{~b}$ & $0,43 \mathrm{~b}$ & $26,73 \mathrm{a}$ \\
\hline & $41,33^{*}$ & 39,65 & 82,13 & 43,66 \\
\hline \multirow{2}{*}{ Desgaste (nota) } & $9,76 \mathrm{a}$ & $9,76 \mathrm{a}$ & $9,56 \mathrm{a}$ & $0,78 \mathrm{~b}$ \\
\hline & 2,12 & 2,87 & 4,16 & 192,05 \\
\hline
\end{tabular}

* - Coeficientes de variação (\%). Médias seguidas pela mesma letra na horizontal, para cada parâmetro analisado, não diferem estatisticamente entre si (Tukey; $\mathrm{P}>0,05$ ). 


\section{CONCLUSÃO}

A madeira de teca, proveniente do Vale do Rio Doce, Minas Gerais, apresentou alta resistência aos fungos Postia placenta, Neolentinus lepideus, Polyporus fumosus nas posições cerne interno, cerne intermediário e cerne externo, com destaque para o cerne externo, que obteve menores perdas de massa. Os fungos Postia placenta e Polyporus fumosus foram os que apresentaram maior agressividade à madeira de teca.

O cerne da madeira de teca foi caracterizado como altamente resistente ao cupim subterrâneo Nasutitermes sp. No entanto, o alburno da madeira de teca não apresentou resistência.

\section{AGRADECIMENTOS}

Os autores agradecem o apoio da Fundação de Apoio à CiênciaeTecnologia doEspíritoSanto-FAPES, porconcederrecursos financeiros para bolsas de estudo, eà Empresa Celulose Nipo Brasileira - CENIBRA S.A., pela doação da madeira utilizada neste trabalho.

\section{REFERÊNCIAS}

ASSOCIAÇÃO BRASILEIRA DA INDÚSTRIA DE MADEIRA PROCESSADA MECANICAMENTE (ABIMCI). Preservação de madeira. In: FÓRUM NACIONAL DAS ATIVIDADES DE BASE FLORESTAL, 2004. Artigo Técnico n.17, 4p. Disponível em: <www.abimci.com.br/index.php?option=com_docman...>. Acesso em: 16 dez. 2010.

AMERICAN SOCIETY FOR TESTING AND MATERIALS. ASTM D-1413: standard test method for wood preservatives by laboratory soil-block cultures. Philadelphia, 2007. 8p.

ASTM D-3345: standard test method for laboratory evaluation of wood and other cellulosic materials for resistance to termites. Philadelphia, 2008. 3p

ASTM D-2017: standard method for accelerated laboratory test of natural decay resistance for woods. Philadelphia, 2005. 5p.

BHAT, K.M. et al. Wood durability of home-garden teak against brown-rot and white-rot fungi. Springer-Verlag. Trees - Struct Func, v.19, p.654-660, 2005. Disponível em: <www.springerlink. com/index/T2473V35344X4111.pdf>. Acesso em: 20 nov. 2010.

CLAUSEN, C.A. Biodeterioration of wood. In: ROSS, R.J. Wood handbook: wood as an engineering material. 100.ed. Madison: USDA, 2010. p.312-327.

FINDLAY, W.P.K. The nature and durability of wood. In: FINDLAY, W.P.K. (Ed). Preservation of timber in the tropics Dordrecht: Matinus Nijhoff/ Dr. W. Junk Publishers, 1985. p.1-13.
JANKOWSKY, I.P. Fundamentos de preservação de madeiras. Piracicaba: Universidade de São Paulo, Escola Superior de Agricultura "Luiz de Queiroz". Documentos Florestais, Piracicaba, n.11, p.1-12, 1990.

PAES, J.B. Resistência natural da madeira de Corymbia maculata (Hook.) K. D. Hill \& L.A.S. Johnson a fungos e cupins xilófagos, em condições de laboratório. Revista Árvore, Viçosa, v.26, n.6, p.761-767, 2002.

PAES, J.B. et al. Eficiência do $\mathrm{CCB}$ na resistência da madeira de algaroba (Prosopis juliflora (Sw) D.C.) a cupins subterrâneos (Nasutiternes corniger Motsch.) em ensaio de preferência alimentar. Ambiência, Guarapuava, v.2, n.1, p.51-64, 2006.

PAES, J.B. et al. Resistência natural de madeiras a fungos xilófago em condições de laboratório. Revista de Ciências Agrárias, Belém, n.47, p.199-210, 2007a.

PAES, J.B. et al. Resistência natural de sete madeiras ao cupim subterrâneo (Nasutitermes corniger Motsch.) em ensaio de preferência alimentar. Revista Brasileira de Ciências Agrárias, Recife, v.2, n.1, p.57-62, 2007b.

PAES, J.B. et al. Eficiência do óleo de candeia na melhoria da resistência da madeira de sumaúma a cupins. Cerne, Lavras, v.16, n.2, p.217-225, 2010.

ROCHA, M.P. Biodegradação e preservação da madeira 5.ed. Curitiba: Fundação de Pesquisas Florestais do Paraná, 2001. 94p. (Série Didática, 1).

RUDMAN, P. et al. Wood quality in plus trees of teak (Tectona grandis L.F.) - as assessment of decay and termite resistance. Silvae Genetica, Bad Orb, v.16, n.3, p.102-105, 1967.

RUDMAN, P. et al. Relationship of tectoquinone to durability in Tectona grandis. Nature, Springer Berlin Heidelberg, v.181, n.4610, p.721-722, 1958.

SGAI, R.D. Fatores que afetam o tratamento para preservação de madeiras. 2000. 130f. Dissertação (Mestrado em Engenharia Civil) - Universidade Estadual de Campinas, Faculdade de Engenharia Civil. Campinas, SP. Disponível em: <http://cutter.unicamp.br/ document $/$ code $=v t 1 s 000212330>$. Acesso em: 11 nov. 2010 .

SILVA, J.C. Deterioração, durabilidade madeiras e preservação. Viçosa: UFV, 2005. 146p.

STEEL, R.G.D.; TORRIE, J.H. Principles and procedures of statistic: a biometrical approach. 2.ed. New York: Mc Graw Hill, 1980. 633p.

SUPRIANA, N. Notes the resistance of tropical wood against termites. Stockholm: The International Research Group on Wood Preservation, 1985. 9p. (Doc. IRG/WP, 1249). 